\title{
Erratum to: Retroperitoneoscopic nephrectomy for non-functioning kidneys related to renal stone disease
}

\author{
Abdulkadir Tepeler • Tolga Akman • \\ Adem Tok • Mehmet Kaba • Murat Binbay • \\ Ahmet Yaser Müslümanoğlu • Ahmet Tefekli
}

Published online: 7 July 2012

(C) Springer-Verlag 2012

Erratum to: Urol Res

DOI 10.1007/s00240-012-0466-2

Dr. Tefekli was affiliated to:

Department of Urology,

Haseki Teaching and Research Hospital,

34360 Istanbul, Turkey

The online version of the original article can be found under doi:10.1007/s00240-012-0466-2.

\footnotetext{
A. Tepeler $(\bowtie) \cdot T$. Akman

Department of Urology, Faculty of Medicine,

Bezmialem Vakif University, Fatih, 34093 Istanbul, Turkey

e-mail: akadirtepeler@yahoo.com
A. Tok · M. Kaba · M. Binbay · A. Y. Müslümanoğlu .
A. Tefekli
Department of Urology, Haseki Teaching and Research Hospital,
34360 Istanbul, Turkey 